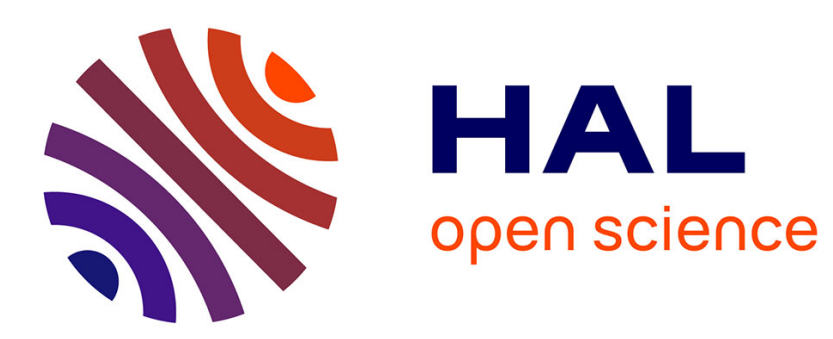

\title{
Mass transport by dislocation climb in the spinel lattice
}

B. Escaig

\section{To cite this version:}

B. Escaig. Mass transport by dislocation climb in the spinel lattice. Revue de Physique Appliquée, 1979, 14 (3), pp.469-474. 10.1051/rphysap:01979001403046900 . jpa-00244616

\section{HAL Id: jpa-00244616 https://hal.science/jpa-00244616}

Submitted on 1 Jan 1979

HAL is a multi-disciplinary open access archive for the deposit and dissemination of scientific research documents, whether they are published or not. The documents may come from teaching and research institutions in France or abroad, or from public or private research centers.
L'archive ouverte pluridisciplinaire HAL, est destinée au dépôt et à la diffusion de documents scientifiques de niveau recherche, publiés ou non, émanant des établissements d'enseignement et de recherche français ou étrangers, des laboratoires publics ou privés. 


\title{
Mass transport by dislocation climb in the spinel lattice
}

\author{
B. Escaig \\ Laboratoire des Structures et Propriétés de l'Etat Solide $\left(^{*}\right)$, \\ Université des Sciences et Techniques de Lille, 59650 Villeneuve d'Ascq, France.
}

(Reçu le 10 novembre 1978, accepté le 1er décembre 1978)

\begin{abstract}
Résumé. - L'analyse théorique des différents flux ioniques se produisant dans un cristal spinelle au cours de la montée des dislocations est présentée, dans le but d'arriver à une description réaliste des dislocations qui montent (charge locale et composition locale au cœur de la dislocation) et des vitesses de montée. Ainsi sont calculés le coefficient effectif de diffusion, la vitesse de montée, la charge électrique dynamique par unité de ligne et la composition du spinelle ( $n$ dans $\left.\left(\mathrm{Al}_{2} \mathrm{O}_{3}\right)_{n} \mathrm{MgO}\right)$ au cœur de la dislocation, en fonction des variables du problème : contrainte, température, composition et diffusivités des espèces élémentaires.

L'effet le plus intéressant est l'écart possible $\Delta n$ dans la composition au cœur d'une dislocation qui monte. Sous certaines conditions, il est suggéré que cet écart peut atteindre des valeurs relativement grandes, $0,5-1$, surtout si $n$ est grand (par ex. $n=3,5$ ) et/ou si les contraintes internes sont fortes, comme dans les conditions habituelles de recuits de montée. De tels écarts pourraient être à l'origine des rubans de faute non planaires observés (ou de plans quelconques dans le réseau) ou encore, de microprécipitations d'une deuxième phase sur le cœur des dislocations.
\end{abstract}

\begin{abstract}
A theoretical formulation of ionic fluxes set up in spinel crystals during dislocation climb is given, with the ultimate aim to achieve a realistic description of climbing dislocations (local core charge and local core composition) and climb rates (i.e. strain rates). Quantities such as the effective diffusion coefficient, the climb velocity, the electric charge per unit length of dislocation, and the spinel composition $\left(n\right.$ in $\left.\left(\mathrm{Al}_{2} \mathrm{O}_{3}\right)_{n} \mathrm{MgO}\right)$ at the core, are derived in terms of the acting stresses, the temperature, the composition $n$, and the element diffusivities. The most interesting effect is the possible composition deviation $\Delta n$ at the core of a climbing dislocation. Under some conditions detailed in the paper, it is suggested that deviations as large as $0.5-1$ could be built up in particular for large $n$ values (e.g. $n=3.5$ ) and /or under the high internal stresses acting during usual climb annealings. Such deviations could explain in turn non-planar faulted ribbons (or ribbons lying apparently on almost any plane in the lattice), or could trigger the microprecipitation of a second phase onto dislocation cores.
\end{abstract}

1. Introduction. - Most of the spinel crystals can only be deformed notably at high temperatures $\left(T>0.6 T_{\mathrm{m}}\right)$ and relatively high stresses $\left(\sigma>10^{-3} \mu\right.$, $\mu$ the shear modulus; see e.g. [1]). It follows that dislocation climb is generally rate controlling for the deformation, either because it controls dislocation glide across the deformation cells, occuring probably within the cell walls $[2,3]$, or even as a pure climb process $[4,5,6]$, occurring at isolated dislocations. Therefore a detailed analysis of climb in spinels is of prime interest for understanding their mechanical properties.

This paper deals with the theoretical formulation of flux equations for the various diffusing species, with the ultimate aim to achieve a realistic description

(*) Associé au C.N.R.S of climbing dislocations (local charge and composition) and climb rates (i.e. strain-rates) in a model as simple as possible. In this view, the following general assumptions are made : (i) the diffusing species are the single ions constitutive of the spinel lattice, (ii) local equilibrium concentration of vacancies is established at the dislocation cores, and (iii) the climbing dislocations are the edge partial dislocations of Burgers vector $1 / 4[1 \overline{1} 0]$ most commonly found either in (110) slip planes, parallel to [001], or in (111) slip planes, parallel to [112]; moreover they are assumed to climb as isolated dislocations, i.e. ignoring the presence of the stacking fault and of the other partial (which should be not unrealistic in the frequently observed case of faults widely extended in the climb plane (110) itself). All these assumptions are open to discussion, but provide as such, a reasonable frame from which further improvements can be brought up. 
Another key for mechanical properties of spinels is to know the actual core structure of their dislocations, as it is pointed out in several recent papers $[1,6,7]$. A main factor here is the local spinel composition $\left(n\right.$ in $\left.\left(\mathrm{Al}_{2} \mathrm{O}_{3}\right)_{n} \mathrm{MgO}\right)$ at the core, which determines the local number of composition vacancies and thereby, the crystallography of splitting, possibly its width, and the fault energy [7, 8, 9] and ultimately perhaps the mobility of the faulted ribbon out of the fault plane [10].

We would point out here that in principle the spinel composition at a climbing dislocation should be different from its equilibrium value in the bulk. This effect stems from the differences in ion diffusivities, much like the Nernst electric field. In contrast to binary ionic compounds, the only charge neutrality requirement does not entail, for spinels like $\left(\mathrm{Al}_{2} \mathrm{O}_{3}\right)_{n} \mathrm{MgO}$, conservation of the chemical composition $n$. The condition of steady state composition, and the principle of minimum entropy production (from the thermodynamics of irreversible processes) produce an additional coupling between ion fluxes which keeps the cation ratio $\mathrm{Al} / \mathrm{Mg}$ at the proper value. Stated differently, composition gradients need be set up throughout the crystal flowing under steady state conditions, in order to counteract the net differences existing between fluxes of the various neutral submolecules. Estimation of the corresponding composition deviation $\Delta n$ at dislocations shows this effect is relatively small under the uniaxial compressive stresses usually applied, $\Delta n \lesssim+0.4$, but it should not be neglected either; for example at temperatures just above the $\gamma / \gamma+\alpha$ boundary in the phase diagram. and for $n \simeq 2$ or 3 , it could trigger a microprecipitation of the $\alpha$-phase onto the dislocation cores.

On the other hand, other useful quantities are derived in this analysis. An effective diffusion coefficient is defined, and the climb velocity is deduced; it does not depend on composition $n$, except through the diffusion constant. Finally the electric charge per unit length of dislocation, due to the Nernst field set up in the crystal as a result of climb, is shown to be rather small, of order a few $10^{-3}$ electron $/ \AA$ for usual applied stresses (about $100 \mathrm{MPa}$ ).

2. The coupling between the ionic fluxes. - Let us consider, as an example, the aluminate spinel $\left(\mathrm{Al}_{2} \mathrm{O}_{3}\right)_{n} \mathrm{MgO}$. When discussing possible $n$ variations, the basic periodicity of the crystal imposes as a rule to keep fixed the number of ionic sites, i.e. to take into account variations in the number of composition vacancies. It follows that the above formula cannot represent correctly this spinel; instead of it, we have to write :

$$
\mathrm{Al}_{2 n} \mathrm{MgV}_{(n-1) / 4} \mathrm{O}_{3 n+1}
$$

where $\mathrm{V}$ is the introduced (neutral) composition vacancies. These are introduced by knowing from
X-ray studies [11] how three $\mathrm{Mg}^{2+}$ ions are replaced by two $\mathrm{Al}^{3+}$ ions when $n$ increases :

$$
\mathrm{Al}_{0}^{3+}+3 \mathrm{Mg}_{\mathrm{t}}^{2+} \rightarrow 3 \mathrm{Al}_{\mathrm{t}}^{3+}+\mathrm{V}_{0}
$$

where indices 0 and $\mathrm{t}$ stand respectively for octahedral and tetrahedral site symmetry. Thus, in a spinel lattice defined by $(3 n+1)$ oxide ions, $(3 n+1) / 4 \mathrm{Mg}$-sites are found of which only one is occupied by $\mathrm{Mg}^{2+}$; hence $(3 / 4)(n-1)$ have been substituted by $\mathrm{Al}^{3+}$ and $(n-1) / 4$ vacancies $\mathrm{V}$ are formed.

Therefore, four different elementary fluxes are to be transported : $J_{\mathrm{Al}}, J_{\mathrm{Mg}}, J_{\mathrm{V}}$ and $J_{0}$, where $J_{\mathrm{i}}=$ flux of species $\mathrm{i}$ by unit time and surface. Let us suppose, next, that the crystal is under conditions $(n, T)$ of the phase diagram such that the $\gamma$ solid solution is stable (upper region). Then, the condition for a steady state composition is, from eq. (1) :

$$
\frac{J_{\mathrm{Al}}}{2 n}=J_{\mathrm{Mg}}=\frac{4 J_{\mathrm{V}}}{n-1}=\frac{J_{0}}{3 n+1}=J_{\mathrm{T}}
$$

where $J_{\mathrm{T}}$ is the flux of molecules as defined in eq. (1). We have assumed here, for the sake of simplicity, that diffusion of $\mathrm{Al}_{\mathrm{t}}^{3+}$ is not different from that of $\mathrm{Al}_{0}^{3+}$, so that only one flux can describe the Al transport.

It is instructive to note that equations (2) are equivalent to two kinds of equations; the first links only $J_{\mathrm{A} 1}, J_{0}$ and $J_{\mathrm{Mg}}$ between them and writes simply :

$$
2 J_{\mathrm{Mg}}+3 J_{\mathrm{Al}}-2 J_{0}=0 \text {. }
$$

It is independent on composition and ensures the charge neutrality of the transported matter; it produces an electrical coupling between fluxes, resulting in an electric term in ion chemical potentials, and setting up a Nernst electric field throughout the crystal [12]. The second group of equations links only $J_{\mathrm{Al}}$, $J_{\mathrm{Mg}}$ and $J_{\mathrm{V}}$, and is formed by the two first equalities in eq. (2). It is independent on oxygen transport, since it regulates only the cation ratio $n=\mathrm{Al} / 2 \mathrm{Mg}$ of the transported matter by its steady state value in the crystal; it produces similarly a compositional coupling between fluxes [13], resulting in a concentration term in ion chemical potentials, and setting up likewise composition gradients in the whole crystal. Obviously, only the gradients of chemical potentials, i.e. the Nernst field and the composition gradients, at dislocation cores, are of interest for mechanical properties.

3. Ionic fluxes induced by dislocation climb. In order to derive equations for the various ionic fluxes, we start from the Fick law, as expressed in terms of chemical potentials by Herring [14]. When ions i enter some small region of the crystal, they expel from it an equal number of point defects so that the free energy of the region increases by $\delta G=\left(\mu-\mu_{1}\right)_{\mathbf{i}}$ where $\mu$ is the chemical potential of the i-ion and $\mu_{1}$, 
of its associated defect in the diffusion process; it follows that the driving force acting on the $\mathrm{i}$ ions is :

$$
F_{\mathrm{T}, \mathrm{i}}=-\nabla\left(\mu-\mu_{1}\right)_{\mathrm{i}}=-\left(\nabla \mu_{\mathrm{i}}+\nabla \mu_{\mathrm{i}}^{*}\right) .
$$

The first term, $F_{\mathrm{i}}=-\nabla \mu_{\mathrm{i}}$, introduces the above coupling forces while the last one, $\nabla \mu_{i}^{*}=-\nabla \mu_{1, \mathrm{i}}$ is fixed by the externally imposed stresses. The corresponding flux $J_{\mathrm{i}}$ is then :

$$
J_{\mathrm{i}}=n_{\mathrm{i}} B_{\mathrm{i}} F_{\mathrm{T}, \mathrm{i}}=-n_{\mathrm{i}} B_{\mathrm{i}}\left(\nabla \mu_{\mathrm{i}}+\nabla \mu_{\mathrm{i}}^{*}\right)
$$

where $n_{\mathrm{i}}$ is the number of $\mathrm{i}$-ions per unit volume; $B_{\mathrm{i}}=D_{\mathrm{i}} / k T$ is their mobility (their velocity $v_{\mathrm{i}}=B_{\mathrm{i}} F_{\mathrm{T}, \mathrm{i}}$ ) and $D_{\mathrm{i}}$ is the diffusion coefficient of $\mathrm{i}$-ions. The gradients $\nabla \mu_{\mathrm{i}}$ and $\nabla \mu_{\mathrm{i}}^{*}$ are now to be calculated.

3.1 EXPRESSION OF THE COUPLING FORCES. - The ion chemical potential is taken simply as :

$$
\mu_{\mathrm{i}}=q_{\mathrm{i}} V+k T \ln X_{\mathrm{i}}
$$

Here $V$ is the electric potential set up in the crystal, $q_{\mathrm{i}}$ the charge of the i-ion and $X_{\mathrm{i}}$, the ratio of i-sites occupied by i-ions. We have made here all the activities equal to unity, neglecting any correlation factor in the diffusion process (independent ionic jumps). It follows that :

$$
\nabla \mu_{\mathrm{i}}=-q_{\mathrm{i}} E+k T \frac{\nabla X_{\mathrm{i}}}{X_{\mathrm{i}}}
$$

where $E$ is the Nernst electric field.

In order to compute the $\nabla X_{\mathrm{i}}$ 's, note that $X_{\mathrm{i}}=n_{\mathrm{i}} / d_{\mathrm{i}}$ with $d_{\mathrm{i}}$ the number of sites available in unit volume, independent on $n_{\mathrm{i}}$, the local filling of the i-sublattice; hence $\nabla X_{\mathrm{i}} / X_{\mathrm{i}}=\nabla n_{\mathrm{i}} / n_{\mathrm{i}}$. Now the $n_{\mathrm{i}}$ 's follow from eq. (1), as for example $n_{\mathrm{Al}}=2 n / \Omega$, where $\Omega$ is the volume occupied by a molecule as defined in this equation. The volume per oxide ion in the spinel lattice being equal to $\omega_{0}=B^{3} / 8 \sqrt{2}$, with $B$ the smallest repeat period, one can write :

$$
\Omega=(3 n+1) \omega_{0}=(3 n+1) B^{3} /(8 \sqrt{2}) .
$$

Finally it comes :

$$
\begin{aligned}
n_{\mathrm{Al}} & =\frac{2 n}{3 n+1} \omega_{0}^{-1} ; \quad n_{\mathrm{Mg}}=\frac{\omega_{0}^{-1}}{3 n+1} ; \\
n_{\mathrm{V}} & =\frac{(n-1) \omega_{0}^{-1}}{4(3 n+1)} ; n_{0}=\omega_{0}^{-1} \\
\left(\frac{\nabla X}{X}\right)_{\mathrm{Al}} & =\frac{\nabla n}{n(3 n+1)} ; \quad\left(\frac{\nabla X}{X}\right)_{\mathrm{Mg}}=-\frac{3 \nabla n}{3 n+1} ; \\
\left(\frac{\nabla X}{X}\right)_{\mathrm{v}} & =\frac{4 \nabla n}{(n-1)(3 n+1)} ; \quad\left(\frac{\nabla X}{X}\right)_{0}=0 .
\end{aligned}
$$

These equations allow us to express the coupling forces $F_{\mathrm{i}}=-\nabla \mu_{\mathrm{i}}$ in terms of the fields $E$ and $\nabla n$, from eq. (4). Li et al. [13] have shown that it follows from eq. (2) and from the principle of minimum entropy production that $\sum_{\mathrm{i}} n_{\mathrm{i}} F_{\mathrm{i}}=0$. This can be easily checked here, from the previous expressions (independently for the electric and for the compositional forces).

\subsection{EXPRESSION OF THE EXTERNALLY IMPOSED FOR-} CES. - Let us consider a positive edge dislocation running along the positive axe $x_{3}$, with its Burgers vector along the positive axe $x_{1}$ (Fig. 1), and let $\sigma_{11}=\sigma$ be the climb stress applied to it $(\sigma<0$ when the extrahalf plane is under a compressive stress as shown in figure 1). Detailed inspection shows that the formation

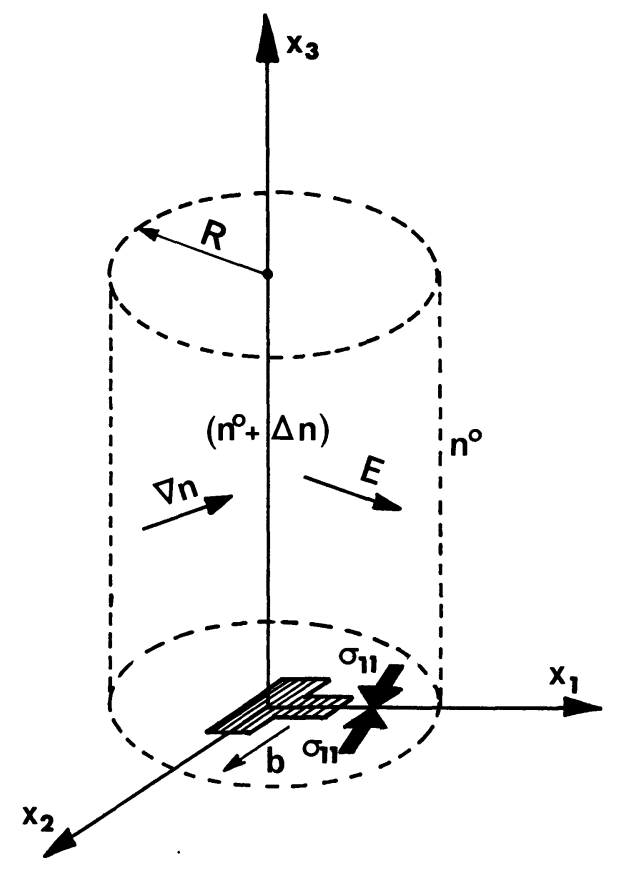

Fig. 1. - Geometry of the climbing edge dislocation under an applied compression stress $\left(\sigma_{11}<0\right)$; the electric field $E$ corresponds to $\alpha \simeq 1$ (see the text)

free energy of a vacancy of i-ion at the dislocation core acted on by $\sigma$ is changed by the amount $-\sigma \omega_{\mathrm{i}}$, where $\omega_{\mathrm{i}}$ is the volume associated with a $\mathrm{i}$-site in the spinel lattice. The defect chemical potential is correspondingly $\mu_{1, \mathrm{i}}=k T \ln \left(C_{\mathrm{i}} / C^{0}\right)=\sigma \omega_{\mathrm{i}}$ at the dislocation, while being taken equal to zero far from it. Because of the cylindrical symmetry of the diffusion problem, the potential distribution is radial around the dislocation line, so that it can be written at the dislocation core :

$$
-\nabla \mu_{\mathrm{i}}^{*}=\nabla \mu_{1, \mathrm{i}}=-K \sigma \omega_{\mathrm{i}}, \quad K \simeq b \ln \left(\frac{R}{b}\right)
$$

$R$ being the distance from dislocation line at which $\mu_{1} \simeq 0$ (see Fig. 1), and $b=B / 2$, the Burgers vector. Thus in eq. (3), $\nabla \mu_{\mathrm{i}}^{*}=K \sigma \omega_{\mathrm{i}}$.

The volume associated with each elementary sites, the $\omega_{i}$ 's, are not easy to define properly. It is easier instead to evaluate the volume associated with neutral submolecules. It is well known in spinel the small 
cations fill up interstices of the sublattice formed by the big oxide ions. Since all the available cation sites are still completely filled for any value of $n$ (by $\mathrm{Al}$, $\mathrm{Mg}$, or $\mathrm{V}$ species), one has always three filled interstices for four oxide ions. Therefore it is not clear to decide, on this only basis, how many volumes per oxide ion, $\omega_{0}$, is to be attributed to one group $\mathrm{Mg}-\mathrm{O}$, for example. However, the result is made clear by looking at the ionic structure of jogs formed on the climbing edge dislocations. Figures 2 and 3 show it for a partial of

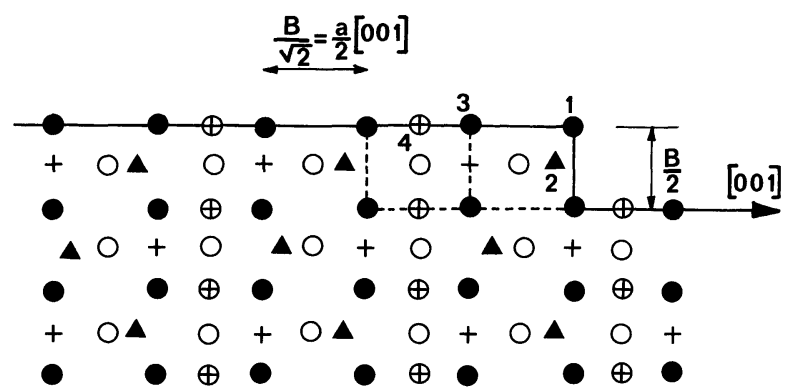

Fig. 2. - Ionic structure of jogs on a partial edge dislocation. The figure shows ions of the pair of extra-half planes (1-10) corresponding to $\mathbf{b}=a / 4$ [1ํㅣ, line along [001], slip plane (110). Plane of composition $\left[\mathrm{AlMgO}_{2}\right]^{+}$:

$$
\text { - } \mathrm{O}^{2-} ; \quad \oplus \mathrm{Al}^{3+} ; \quad \boldsymbol{\Delta} \mathrm{Mg}^{2+} \text {. }
$$

Plane of composition $\left[\mathrm{AlO}_{2}\right]^{-}$:

$$
\mathrm{O}^{2-} ; \quad+\mathrm{Al}^{3+}
$$

$B$ is the smallest repeat period $a / 2[1 \overline{1} 0]$, and a is the cubic lattice parameter. Dashed lines show successive positions of the partial jog in one $\left[\mathrm{AlMgO}_{2}\right]^{-}$plane during evaporation of ions in the sequence $1,2,3,4$

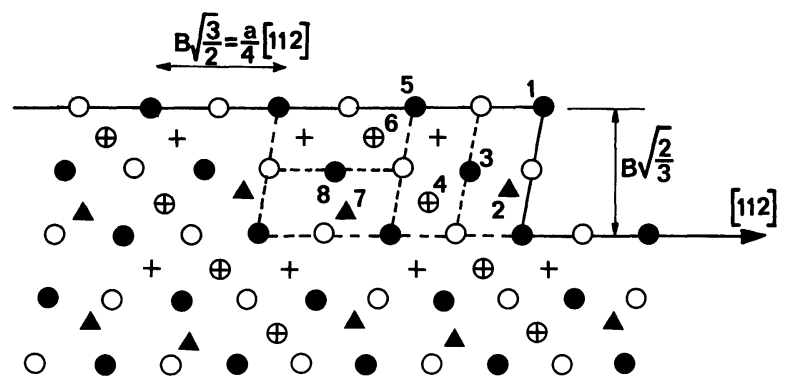

Fig. 3. - Same as in figure 2 but for a partial edge dislocation

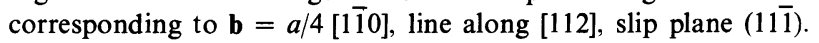
Dashed lines show successive positions of the partial jog in one $\left[\mathrm{AlMgO}_{2}\right]^{-}$plane during evaporation of ions in the sequence 1,2 , $3,4,5,6,7,8$.

Burgers vector $1 / 4$ [1 $1 \overline{1} 0]$ lying respectively either in a (110) plane parallel to [001], or in a (11) plane parallel to [112] (only the case $n=1$ is shown; other values of $n$ would consist simply to distributing a few vacancies $\mathrm{V}$ among the $\mathrm{Al}_{0}^{3+}$ ions, and replacing them on $\mathrm{Mg}$-sites). There it is clearly shown that a group $\mathrm{Mg}-\mathrm{O}$ belongs to one $(1 \overline{1} 0)$ plane in the pair of extra-half planes, the one which has the composition $\mathrm{AlMgO}_{2}$ - a slice of thickness $B / 4$. The sequence of evaporation/ condensation being in this plane .../Al-O/Mg-O/... the surface per group is equal to the surface per oxide ion in the plane, that is $B^{2} / 2 \sqrt{2}$. Thus the volume $\Omega^{\prime}$ associated to $\mathrm{Mg}-\mathrm{O}$ in the spinel lattice does not depend on $n$ and is :

$$
\Omega^{\prime}=\omega_{0}=B^{3} / 8 \sqrt{2}
$$

so that one has : $\nabla \mu_{\mathrm{Mg}}^{*}+\nabla \mu_{0}^{*}=K \sigma \Omega^{\prime}$.

Incidently, it can be noted that jog climb of an edge with slip plane $(11 \overline{1})$ is geometrically much more complicated (Fig. 3) than for a slip plane (110) (Fig. 2), and involves probably a periodic perturbation of the jog configuration along the line. We do not take into account this effect in our simplified approach, since we have assumed dislocations are perfect sinks for vacancies.

3.3 IONIC FLUXES, COMPOSITION GRADIENTS, AND NeRNST FIELd at a Climbing dislocation. - Eq. (2), (3) and (4) allow us to write down the flux equations of the system :

$$
\begin{aligned}
& -\frac{J_{\mathrm{T}} \Omega}{B_{\mathrm{A} 1}}=\nabla \mu_{\mathrm{A} 1}^{*}+k T \frac{\nabla n}{n(3 n+1)}-3 e E \\
& -\frac{J_{\mathrm{T}} \Omega}{B_{\mathrm{Mg}}}=\nabla \mu_{\mathrm{Mg}}^{*}-3 k T \frac{\nabla n}{3 n+1}-2 e E \\
& -\frac{J_{\mathrm{T}} \Omega}{B_{\mathrm{V}}}=\nabla \mu_{\mathrm{V}}^{*}+4 k T \frac{\nabla n}{(n+1)(3 n+1)} \\
& -\frac{J_{\mathrm{T}} \Omega}{B_{0}}=\nabla \mu_{0}^{*}+2 e E
\end{aligned}
$$

where $e$ is the absolute electron charge. Taking the values of all the space functions, $J_{\mathrm{T}}, \nabla \mu_{\mathrm{i}}^{*}, \nabla n$ and $E$, at the dislocation core, and with the help of eq. (5) $\left(\sum_{i} \omega_{i}=\Omega\right),(6)$ and $(7)$, it comes out :

$$
\begin{array}{r}
-\frac{J_{\mathrm{T}} \Omega}{B}=\nabla \mu_{\mathrm{mol}}^{*}=K \sigma \Omega=(3 n+1) K \sigma \omega_{0} \\
3 k T \frac{\nabla n}{3 n+1}-\frac{J_{\mathrm{T}} \Omega}{B^{\prime}}=\nabla \mu_{\mathrm{Mg}}^{*}=K \sigma \Omega^{\prime}=K \sigma \omega_{0} \\
2 e E+3 k T \frac{\nabla n}{3 n+1}-\frac{J_{\mathrm{T}} \Omega}{B_{\mathrm{Mg}}}=\nabla \mu_{\mathrm{Mg}}^{*}=K \sigma \omega_{\mathrm{Mg}}
\end{array}
$$

which can be solved in $J_{\mathrm{T}}, \nabla n$ and $E$. Here the effective diffusion constants $D$ and $D^{\prime}$ have been introduced through $B$ and $B^{\prime}(B=D / k T)$ :

$$
D^{\prime}=\frac{D_{\mathrm{Mg}} D_{0}}{D_{\mathrm{Mg}}+D_{0}}
$$

and :

$$
\begin{aligned}
D= & \frac{D_{\mathrm{Al}} D_{\mathrm{Mg}} D_{0} D_{\mathrm{v}}}{2 n D_{\mathrm{Mg}} D_{0} D_{\mathrm{v}}+D_{\mathrm{Al}} D_{0} D_{\mathrm{v}}+} \\
& +(3 n+1) D_{\mathrm{Al}} D_{\mathrm{Mg}} D_{\mathrm{v}}+\frac{n-1}{4} D_{\mathrm{Al}} D_{\mathrm{Mg}} D_{0}
\end{aligned}
$$


This latter equation can be simplified by noting that the constant $D_{\mathrm{v}}$ should be much larger than all the others. This is because a vacancy $V$ has always a few near-neighbour ions able to jump into, making it travel one atomic spacing, while an ion i has around it a much smaller number of vacancies to allow it to jump. Therefore we can write :

$$
D=\frac{D_{\mathrm{Al}} D_{\mathrm{Mg}_{\mathrm{g}}} D_{0}}{2 n D_{\mathrm{Mg}} D_{0}+D_{\mathrm{Al}} D_{0}+(3 n+1) D_{\mathrm{Al}} D_{\mathrm{Mg}}} .
$$

Solution of eq. (8) is straightforward. Instead of computing $J_{\mathrm{T}}, \nabla n$ and $E$, we have rather computed more meaningful quantities :

- the climb velocity $: v_{\mathrm{c}}=2 \pi J_{\mathrm{T}} \Omega$,

- the composition deviation at the dislocation : $\Delta n=-\nabla n / K$,

- the electric charge per unit length $Q=2 \pi \varepsilon_{0} b E$

One finds :

$$
\begin{gathered}
v_{\mathrm{c}}=\frac{2 \pi}{\ln (R / b)} \cdot \frac{D_{0}(1-\alpha)}{b} \cdot \frac{\sigma \Omega^{\prime}}{k T} \\
\Delta n=-\frac{(3 n+1) \alpha}{3} \cdot \frac{\sigma \Omega^{\prime}}{k T} \\
Q=\varepsilon_{0} \frac{\pi \ln (R / b)}{e}\left(\frac{1}{2}-\alpha\right) \cdot \sigma \Omega^{\prime} .
\end{gathered}
$$

Here : $R \simeq 0.5 \rho^{-1 / 2}$ ( $\rho$, the dislocation density), $b=0.5 \mathrm{~B}, \Omega^{\prime}=B^{3} /(8 \sqrt{2}), \sigma=+\sigma_{11}$, and :

$$
\alpha=\left[1+\frac{3 n+1}{2 n} \frac{D_{\mathrm{Al}}}{D_{0}}\right]^{-1} .
$$

We have assumed that $\left(D_{\mathrm{Al}} / D_{\mathrm{Mg}}\right)$ and $\left(D_{0} / D_{\mathrm{Mg}}\right)$ are negligible as compared to unity, which is certainly valid for spinels, and that $\omega_{\mathrm{Mg}} \simeq 0.5 \omega_{0}=0.5 \Omega^{\prime}$, which is suggested by figures 2 and 3 .

The parameter $\alpha$ is hard to know precisely; it is a number between 0 and $1:$ if it is believed that oxide ions are the slowest species to diffuse, as it has been often stated in some papers $[3,4,5,6,18]$, then $\alpha$ is small : $\alpha \simeq(2 n / 3 n+1)\left(D_{0} / D_{\mathrm{Al}}\right)$. In fact, no reliable data are available on the diffusion of $\mathrm{Al}$, but some estimations from chemical diffusion data have proposed a coefficient $D_{\mathrm{Al}}<D_{0}[2,15]$; if this is accepted, then $\alpha$ increases near to unity.

Finally, the nature of diffusing species, elementary ions as assumed above versus neutral submolecules, is not known either. Evidences for climb by transport of neutral vacancy pairs have been presented in halide crystals by Poirier [16] and Pontikis [17]. In the case of diffusion in spinel by groups $A=\mathrm{Al}_{2} \mathrm{O}_{3}$ and $B=\mathrm{MgO}$, the above analysis applied to the compound $A_{n} B V_{(n-1) / 4}$ leads to very similar results except for the charge $Q$ which is now zero. Under the reasonable assumption $D_{A}<n D_{B}$, which states that the molecule $\mathrm{MgO}$ is more mobile than $\mathrm{Al}_{2} \mathrm{O}_{3}, \Delta n$ is still given by eq. $(10 b)$ with $\alpha=1-(3 n+1 / n) \quad\left(D_{A} / D_{B}\right) \simeq 1$, while the climb velocity writes now :

$$
v_{\mathrm{c}}=\frac{2 \pi}{\ln (R / b)} \cdot \frac{(3 n+1) D_{A}}{n} \cdot \frac{\sigma \Omega^{\prime}}{k T}
$$

where $D_{A}$ stands for $D_{\mathrm{Al}_{2} \mathrm{O}_{3}}$ and $D_{B}$ for $D_{\mathrm{MgO} \text {. }}$

4. Discussion and conclusion. - A precise knowledge of diffusion constants in spinels is not yet available; for the time being, we can only speculate from supposed values. For the simplicity of discussion, let us consider the case $\alpha \simeq 1$, either because $D_{\mathrm{Al}}<D_{0}$, or because diffusion occurs by movements of neutral groups of ions. In the opposite case where $\alpha \ll 1$ (i.e. $D_{0}<D_{\mathrm{Al}}$ ), $D_{0}$ would be dominant in the climb velocity instead of $D_{\mathrm{Al}}, \Delta n$ would be very small and $Q$ would change its sign, being positive under tension and negative under compression.

The climb velocity expression, $(10 a)$ or $\left(10^{\prime} a\right)$ show it is quite similar to the one used for metals, but with the volume entering the work term equal to a few $\Omega^{\prime}\left(\Omega^{\prime} \simeq 17.2 \AA^{3}\right.$ in aluminate spinels), depending slightly on the composition $n$.

The charge $Q$ is at any rate rather small. Taking for example :

$$
\begin{gathered}
\rho \simeq 10^{12} \mathrm{~m}^{-2}, \quad\left|\frac{1}{2}-\alpha\right|=0.5, \\
\sigma=118 \mathrm{MPa}\left(=10^{-3} \mu\right),
\end{gathered}
$$

it comes $:|Q|=0.9 \times 10^{-3} e / \AA$ which is very weak.

Finally the most interesting effect is the possible change in composition $\Delta n$. Note first, that $\Delta n$ is always positive for applied uniaxial compressive stresses (and negative under tension), i.e. the core is enriched with alumina. This is quite expected, since under a compression all the edges are evaporating ions of their extra-half planes into the lattice; assuming $\alpha \simeq 1$, either $\mathrm{Al}^{3+}$ or $\mathrm{Al}_{2} \mathrm{O}_{3}$ is the slowest species to be evaporated, hence with which the cores are enriched. As a basis for discussion, the following deviations $\Delta n$ at a climbing dislocation are computed from eq. (10b) and

$$
\begin{gathered}
\alpha \simeq 1, \quad T=1873 \mathrm{~K}, \\
\sigma_{0}=-354 \mathrm{MPa}=-3 \times 10^{-3} \mu
\end{gathered}
$$

(compressive stress) :

$$
\begin{aligned}
& n=1 \quad 1.8 \quad 3.5 \\
& \Delta n=0.31 \quad 0.50 \quad 0.90 \text {. }
\end{aligned}
$$

Applied stresses are usually sensibly less than the above value $\sigma_{0}$ (typically $0.3-0.5 \sigma_{0}$ ), thus involving $\Delta n$-values in the range 0.1-0.4. In contrast, the forces due to dislocation interactions (internal stresses) or to dislocation line tension (acting during annealings) are generally equal to or even higher than $\sigma_{0}$. 
Examples of such forces are observed in a number of experiments either during high temperature deformation $[3,4,5,6,20]$ or during controlled annealings [20]. Among these, two main situations are found, where climb forces should be high :

(i) line tension effects at non equilibrated triple nodes, when the slip planes of their arms meet only at one point, forcing thus one of the arms to climb $[19 a]$;

(ii) line tension forces which drive, during high temperature annealing, the climb growth of meshes of the dense dislocation network built up by a previous strain. Analysing the work done by line tension during this process, Friedel has shown [19b] the equivalent climb stress to be $\sigma=\mu b\left(\rho^{1 / 2}\right)$; application to the present case gives $\sigma>3 \times 10^{-3} \mu$ for a dislocation density $\rho>1.2 \times 10^{13} \mathrm{~m}^{-2}$, while such figures as $10^{13}-10^{14} \mathrm{~m}^{-2}$ are commonly observed $[4,5,20]$. Therefore, $\Delta n$ values in the range $0.5-1$ are to be expected in such experiments.

Such local changes in composition might be the origin of some recently observed behaviours, or some others can be predicted. Clearly, either they introduce extra composition vacancies and tetrahedral $\mathrm{Al}^{3+}$ onto the fault plane of ribbons formed by split dislocations ; or they introduce simply ledges along these faulted ribbons, or corrugations, which do not conserve composition. A detailed analysis of such defects, and of their consequences on the increase in mobility of the ribbons out of their planes is to be published shortly [10], but for the present it is conceivable they should result in an apparent stacking fault plane lying on almost any plane in the lattice, or even being not planar. This might explain the numerous observations of unexpected fault planes (not conserving composition) and non planar ribbons, as in experiments of the Cleveland group [4, 5, 10], most of the time in situations which favour higher values for $\Delta n$ : high strain-rate and high dislocation density (e.g. constant strain rate test - at usual rates $\varepsilon \simeq 10^{-4} \mathrm{~s}^{-1}$ - as opposed to creep tests), fast cooling rate (designed to quench configurations under stress), faults observed at a dislocation node (see in particular in [20] figures $3 c$ and 9 of type II nodes where only one arm is found not to conserve composition, suggesting the above situation (i)), preferably high $n$ value ( $n=3.5$ in [20]), and finally the role played by climb annealing ("Annealing resulted in fault planes $\{112\}$ and $\{113\} \ldots$ but the faults are frequently curved and twisted » [20], as opposed to generally simpler faults found just after deformation and before annealing; see also in $[4,5]$ the same trend in dislocation habits before and beyond $\sim 3 \%$ strain at which a strong work - softening occurs reducing the dislocation density by a factor $10^{4}$ ).

Such behaviours contrast strongly with deformation under softer conditions, i.e. creep tests done at a low strain-rate, low dislocation density and low $n(n=1)$ [6]. There, dislocations split in early slip, almost always in simple, composition conservative planes [8] Note that even in this case, the dissociation plane is much more random when $\mathrm{n}$ increases, or at dislocation nodes when equilibrium climb has occured.

Finally, a last effect might be expected. The composition deviation $\Delta n$ could trigger the microprecipitation of a second phase onto the dislocation core each time the value $n+\Delta n$ reaches the threshold for exsolution of $\alpha-\mathrm{Al}_{2} \mathrm{O}_{3}$. This should take place either because the condition $(n, T)$ falling just above the boundary, in the $\gamma$-solid solution region of the phase diagram (say a few $10^{\circ}$ above), the increment $\Delta n$ allows to cross over toward the two phase region; or because the condition $(n, T)$ being already metastable (below the boundary), the increment $\Delta n$ increases the thermodynamic force so much that it starts exsoluting. In these cases, edge dislocation cores would become, simply by the $\Delta n$ effect, the nuclei of the phase transformation, resulting mechanically in a strong pinning.

\section{References}

[1] Veyssière, P. and Rabier, J., J. Physique Colloq. 39 (1978) C2-86.

[2] Doukhan, N., Duclos, R. and Escaig, B., J. Physique Colloq. 34 (1973) C9-379 also, Duclos, R., Thèse de $3^{\text {e }}$ Cycle, Université de Lille, 1974.

[3] VeYssıère, P., Thèse d'Etat, Université de Poitiers (1977).

[4] Mitchell, J. E., Hwang, L. and Heuer, A. H., J. Mater. Sci. 11 (1976) 264.

[5] Donlon, W. T., M. Sc. Thesis, Case Western Reserve University Cleveland (1977).

[6] Duclos, R., Doukhan, N. and Escaig, B., J. Mater. Sci 13 (1978) 1740.

[7] Veyssière, P., Rabier, J., Garem, H. and Grilhe, J., Phil. Mag. in press.

[8] Doukhan, N., Duclos, R. and Escaig, B., to appear.

[9] Doukhan, N. and Escaig, B., J. Physique Lett. 35 (1974) L-181.

[10] EsCAIG, B., Workshop on the Interaction of Point Defects. Dislocations in Oxides, Bellevue, 1978; to appear.
[11] Jagodzinski, H., Bull. Soc. Fr. Minerall. XC (1967) 575.

[12] Ruoff, A. L., J. Appl. Phys. 36 (1965) 2903.

[13] Che-Yu Li., Blakely, J. M. and Feingold, A. H., Acta Metall. 14 (1966) 1397.

[14] Herring, C., J. Appl. Phys. 21 (1950) 437; see also for ex. POIRIER, J. P., Plasticité à haute température des solides cristallins (Eyrolles), 1976, p. 156.

[15] Whitney, W. P. and Stubican, V. S., Amer. Ceram. Soc. Bull. 49 (1970) 388.

[16] Poirier, J. P., Phil. Mag. 26 (1972) 701.

[17] Pontikis, V., Thèse d'Etat, Université de Paris (1977) ; also Batra, A. and Slifkin, L. M., J. Phys. C. Sol. Phys. 9 (1976) 947.

[18] Ando, K. and Orshi, Y., J. Chem. Phys. 61 (1974) 625.

[19] Friedel, J., Dislocations (Pergamon Press), 1964, (a) p. 109 ; (b) p. 239.

[20] Donlon, W. T., Mrtchell, T. E. and Heuer, A. H., Phil. Mag., to appear. 